\title{
Robotic surgery: Maximizing the potential of a minimally invasive platform
}

\author{
Jason J. Han, MD, and Pavan Atluri, MD
}

\author{
From the Division of Cardiovascular Surgery, Department of Surgery, University of Pennsylvania, Philadelphia, \\ $\mathrm{Pa}$. \\ Disclosures: Authors have nothing to disclose with regard to commercial support. \\ Received for publication Nov 1, 2017; accepted for publication Nov 9, 2017; available ahead of print Dec 6, 2017 \\ Address for reprints: Pavan Atluri, MD, Division of Cardiovascular Surgery, Hospital of the University of Penn- \\ sylvania, 3400 Spruce St, 6 Silverstein Pavilion, Philadelphia, PA (E-mail: Pavan.Atluri@uphs.upenn.edu). \\ J Thorac Cardiovasc Surg 2018;155:947-8 \\ $0022-5223 / \$ 36.00$ \\ Copyright (C) 2017 by The American Association for Thoracic Surgery \\ https://doi.org/10.1016/j.jtcvs.2017.11.014
}

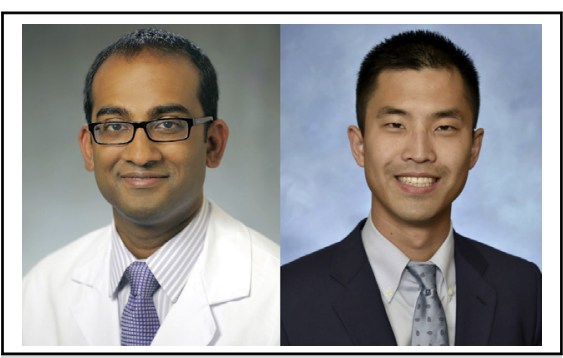

Pavan Atluri MD (Left), and Jason J. Han MD (Right)

\section{Central Message}

Robot-assisted mitral valve surgery is a safe, durable, and effective approach. The learning curve is steep and is predicated on an existing mastery of anatomy, pathology, and open surgical techniques.

See Article page 943.

\section{desired outcomes.}

The featured article by Dearani ${ }^{4}$ in this issue of the Journal is an insightful foray into these expert institutions' perspectives. He accomplishes precisely what any author should aspire to do in an expert review-succinct distillation of the core principles reflected in the data, embellished by nuanced insights that arise from one's own extensive clinical experiences. In remarking on the excellent outcomes reported by Gillinov and colleagues, ${ }^{5}$ evidenced in their near-perfect success rate $(98 \%)$ of mitral repair with less than $1 \%$ early mortality, the author makes remarkably clear the 2 factors of utmost significance that enable success in robot-assisted mitral repair: careful patient selection and workup combined with a high volume of cases, enabling institutional familiarity with the technology and rapid transcendence of the learning curve. Experience leads to refinement of technique and protocol, ever-decreasing crossclamp times and the need for open-conversion. He astutely points out the detail of $2 \%$ stroke rate in the first 500 patients decreasing to $0.8 \%$ by the latter 500 patients. We glean from his insight that robotic-assisted mitral surgery may not inherently promise excellent outcomes but with rigorous learning and commitment, an institution can achieve near-impeccable results with minimal comorbidities.

This has similarly been our own experience as we have adapted this valuable technology. As stated previously, the key principle in translating this therapy to patients is a deep understanding of MV anatomy, pathology, and repair techniques. It is vital to maintain the core principles of $\mathrm{MV}$ repair that have resulted in excellent long-term outcomes that cardiologists and patients alike have come to expect. The robotic platform has reintroduced 3-dimensional visualization as well as wrist motion into the minimally invasive platform that does not exist with standard endoscopically assisted MV platforms. ${ }^{6}$ Even at our center, where we have gained significant experience in the port access platform, we have appreciated these advantages in MV repair. ${ }^{7}$ However, the learning curve should not be minimized. A commitment to the technology with patience, dedication, and focus is vital, as Dr Dearani has elucidated. As newer platforms are introduced by competitors, further advantages and improvements should be evident, hopefully minimizing the learning curve.

Ultimately, we congratulate Dr Dearani on his thoughtful review. It is not only an insightful analysis of the manuscript by Gillinov and colleagues but also a demystification of the niche landscape of robotic-assisted cardiac surgery. Its advantages seem clear as long as the procedure is performed on the "right" patients under the "right" conditions. Through his words, the readers will be left with what is better than either "hype or hope" —an insight that is balanced, realistic, and rare.

\section{References}

1. Suri RM, Dearani JA, Mihaljevic T, Chitwood WR Jr, Murphy DA, Trento A, et al Mitral valve repair using robotic technology: safe, effective, and durable. J Thorac Cardiovasc Surg. 2016;151:1450-4. 
2. Suri RM, Taggarse A, Burkhart HM, Daly RC, Mauermann W, Nishimura RA, et al. Robotic mitral valve repair for simple and complex degenerative disease: midterm clinical and echocardiographic quality outcomes. Circulation. 2015; 132:1961-8.

3. Chitwood WR Jr, Rodriguez E, Chu MW, Hassan A, Ferguson TB, Vos PW, et al. Robotic mitral valve repairs in 300 patients: a single-center experience. J Thorac Cardiovasc Surg. 2008;136:436-41.

4. Dearani JA. Robotic heart surgery: hype or hope? J Thorac Cardiovasc Surg. 2018;155:943-4.
5. Gillinov AM, Mihaljevic T, Javadikasgari H, Suri RM, Mick SL, Navia JL, et al. Early results of robotically assisted mitral valve surgery: analysis of the first 1000 cases. J Thorac Cardiovasc Surg. 2018;155:82-91.

6. Lehr EJ, Guy TS, Smith RL, Grossi EA, Shemin RJ, Rodriguez E, et al. Minimally invasive mitral valve surgery III: training and robotic-assisted approaches. Innovations (Phila). 2016:11:260-7.

7. Vallabhajosyula P, Wallen TJ, Solometo LP, Fox J, Vernick WJ, Hargrove WC III. Minimally invasive mitral valve surgery utilizing heart port technology. J Card Surg. 2014;29:343-8 